\title{
Investigation of Nanocomposites Made with Poly(methacrylic acid-co-methyl methacrylate)/ poly(N-vinyl-2-pyrrolidone)/Multi-walled Carbon Nanotubes
}

\author{
Liu Guoqin, Miao Wei \\ College of Material Science and Engineering, Henan University of Technology, China \\ Shangguan Lin-jian \\ School of Mechanical Engineering, North China University of Water Conservancy and \\ Electric Power, China
}

\begin{abstract}
Poly(methacrylic acid-co-methyl methacrylate) (P(MAA-co-MMA)) was prepared in the presence of poly(N-vinyl-2-pyrrolidone) (PVP) and multiwalled carbon nanotubes (MWNTs) via ultrasonic assisted solution free radical polymerization, i.e., $\mathrm{P}(\mathrm{MAA}-\mathrm{co}-\mathrm{MMA}) / \mathrm{PVP} / \mathrm{MWNTs}$ nanocomposites. The morphology, glassy-state storage modulus, thermal behavior and swelling characteristics of P(MAA-co-MMA)/PVP/MWNTs nanocomposites were investigated. Scanning electron micrographs (SEM) revealed that MWNTs at low concentration could be uniformly dispersed into P(MAA-co-MMA)/PVP blends. With increasing MWNTs weight fraction, the average glassy-state modulus, glass transition temperatures and decomposition temperature of the nanocomposites increased, but their swelling characteristics decreased.
\end{abstract}

Keywords: $P(M A A-c o-M M A) / P V P / M W N T$, nanocomposites, morphology, dynamic mechanical properties.

\section{Introduction}

Polymer nanocomposites are a class of materials in which nano-sized inorganic fillers are dispersed in an organic polymer matrix and widely studied class of materials ${ }^{[1-4]}$; the polymer matrix includes homopolymers, copolymers and blends. Among them, polymers/carbon nanotubes (CNTs) nanocomposites have gained tremendous interest due to their high durability, high strength, lightweight, design and process flexibility, etc ${ }^{[5-9]}$. CNTs are proven to be ideal fillers because of their low density, high aspect ratio, large specific surface area and high electrical conductivity for polymer composites to improve the electrical conductivity, thermal conductivity and mechanical properties, together with the need for only small volume fractions ${ }^{[10-12]}$. CNTs can be present as single-walled carbon nanotubes (SWNTs) or multi-walled carbon nanotubes (MWNTs). SWNTs are a one atomic layer thick hollow cylinder of carbon with diameters in the order of a nanometer and lengths ranging from hundreds of nanometers to micrometers. By comparison, MWNTs diameters range from 5 to a few hundred nanometers because their structure consists of many concentric cylinders held together by van der Waals forces ${ }^{[13,14]}$. Although SWNTs have much lower loading versus MWNTs to achieve the same electrical properties, enhancing mechanical properties even further ${ }^{[15]}$, the difficult in dispersing SWNTs uniformly is still a big challenge for the use of SWNT in real application. In addition, the high cost and difficulty in purification also limits the large-scale production of SWNTs. In contrast, for chemical vapor deposition (CVD) growth MWNTs, the cost is much lower ${ }^{[16]}$. Therefore, MWNTs have been widely used as reinforcing fillers over the past few years $^{[17]}$.

In the present study, poly(methacrylic acid-co-methyl methacrylate) (P(MAA-co-MMA)) networks were prepared and crosslinked by radical copolymerization of MAA with MMA in the presence of poly(N-vinyl-2pyrrolidone) (PVP) and MWNTs via ultrasonic assisted solution free radical polymerization, i.e., P(MAA-coMMA)/PVP/MWNTs nanocomposites.

PVP is among the most common materials employed in medicine and in other applications interfacing with biological systems because of its excellent biocompatibility with living tissues and extremely low cytotoxicity ${ }^{[18,19]}$. PVP can form stable complexes with polyacids through hydrogen bonding, and this kind of complexes is the most stable of the hydrogen-bonded complexes ${ }^{[20,21]}$. The addition of MWNTs to P(MAAco-MMA)/PVP blends may improve the mechanical and thermal properties. The effect of different weight percent loadings of MWNTs on the morphological, dynamic mechanical, and thermal properties of P(MAAco-MMA)/PVP/MWNTs nanocomposites have been investigated.

\section{Experimental}

MWNTs (the element of composition (atom\%): C: 98.36, O: 1.30, Al: 0.23, S: 0.05, Fe: 0.06) were purchased from Shenzhen Nano-Technologies Port Co. Ltd., China, with a purity of above $96 \%$, average length of microns, and surface area of $4.26 \mathrm{~m}^{2} / \mathrm{g}$ and its size analysis was 
performed on a Microtrac S3000 analyzer (Microtrac Software Co., USA). Methacrylic acid (MAA), methyl methacrylate (MMA), 2,2'-azobis(isobutyronitrile) (AIBN) and N,N'-methylenebis(acrylamide) (MBAA) were analytical grade from Chengdu Reagent Factory. Poly(N-vinyl-2-pyrrolidone) (PVP) with the $\mathrm{Mw}=58000$ (Aldrich) was used as received, which also played a role of an organic dispersant. MAA and MMA were distilled under reduced pressure before use. AIBN, used as a radical initiator, was recrystallized from ethanol solution. MBAA was used as a cross-linker without further purification.

MWNTs were treated by immersing in $3 \mathrm{~mol} / \mathrm{l}$ nitric acid and refluxing for 6 hours, subsequently washed with distilled water until the $\mathrm{pH}$ of the MWNTs solution approached 7. The MWNTs with dimethyl sulfoxide (DMSO) were sonicated in a two-necked flask for $20 \mathrm{~min}$. Then, MAA and MMA monomer, and PVP were added into the flask and stirred for $10 \mathrm{~min}$, which were further sonicated for $10 \mathrm{~min}$. AIBN (0.01 mol/L) and MBAA $(0.02 \mathrm{~mol} / \mathrm{L})$ were added and nitrogen gas was purged into the flask to remove oxygen. The mixtures were sonicated using a bath sonicator for 1 hour. Polymerization was carried out with constant stirring at $60{ }^{\circ} \mathrm{C}$ for $30 \mathrm{~min}$. Then, the reaction mixture injected into the space between two glass plates separated by polyethylene spacers ( $3 \mathrm{~mm}$ thick) or into a cylindrical glass tube with a diameter $7 \mathrm{~mm}$ and continued to polymerize at $55^{\circ} \mathrm{C}$ for 24 hours. Scheme 1 shows the flowchart of the procedure for the preparation of P(MAA-co-MMA)/PVP/MWNTs nanocomposites.

The concentration of MAA and MMA were optimized by weight percent conversion of polymerization and MAA (1.0 mol/L), MMA (1.0 mol/L), and PVP (25 wt\% of the entire monomers) were kept constant for variation of MWNTs. The prepared P(MAA-co-MMA)/PVP/ MWNTs nanocomposites were quenched and then dried under vacuum at room temperature for 10 days to remove unreacted monomers.

SEM observation was carried out with a JSM-5900LV scanning electron microscopy; the samples were fractured in liquid nitrogen, and the resulting fracture surfaces were then coated with gold. Thermogravimetric analysis (TGA) measurement was performed using TGA-7 (PerkinElmer); the sample was heated under air from room temperature to $620^{\circ} \mathrm{C}$ at a heating rate of $10^{\circ} \mathrm{C} / \mathrm{min}$. The dynamic mechanical analyses (DMA) were carried out with a Du Pont 983 DMA at a fixed oscillation amplitude of $0.1 \mathrm{~mm}$ and under nitrogen gas purging. The frequency of $1 \mathrm{~Hz}$ was chosen for all the samples examined.

P(MAA-co-MMA)/PVP/MWNTs nanocomposites may be used for potential biomaterials, such as wound dressing. It would be of interest to study its swelling characteristics, which indicated the ability of P(MAA-coMMA)/PVP/MWNTs nanocomposite gels in absorption of fluids. Swelling characteristics of samples in double distilled water were measured by weighing their water content rise. Approximately $1 \mathrm{~g}$ of completely dried and extracted samples were weighed and then immersed into $500 \mathrm{ml}$ of double distilled water. Swelling was performed at $27{ }^{\circ} \mathrm{C}$ in thermostatically controlled water bath till reaching to an equilibrium state. Then the swelled samples were withdrawn from double distilled water and weighed after gentle surface wiping using absorbent paper. The equilibrium degree of swelling $(E S)$ and equilibrium water content $(E C)$ were calculated respectively, as follows:

$$
\begin{aligned}
& E S=\left(W_{S}-W_{d}\right) / W_{d} \times 100 \\
& E C=\left(W_{s}-W_{d}\right) / W_{s} \times 100
\end{aligned}
$$

Where $W s$ is the swollen weight of the sample at equilibrium state and $W d$ is the final dry weight of the extracted sample.

\section{Results and Discussion}

The diameter distribution of as-received MWNTs was measured, as shown in Figure 1. The diameter of $93 \%$

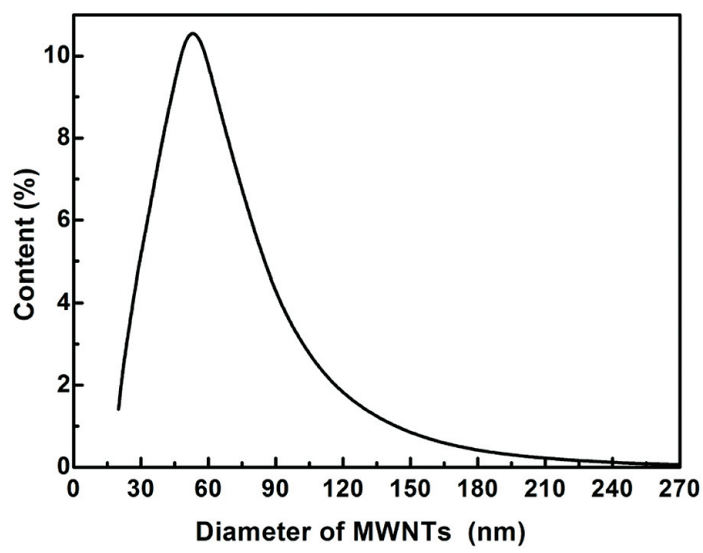

Figure 1. Diameter distribution of as-received MWNTs.

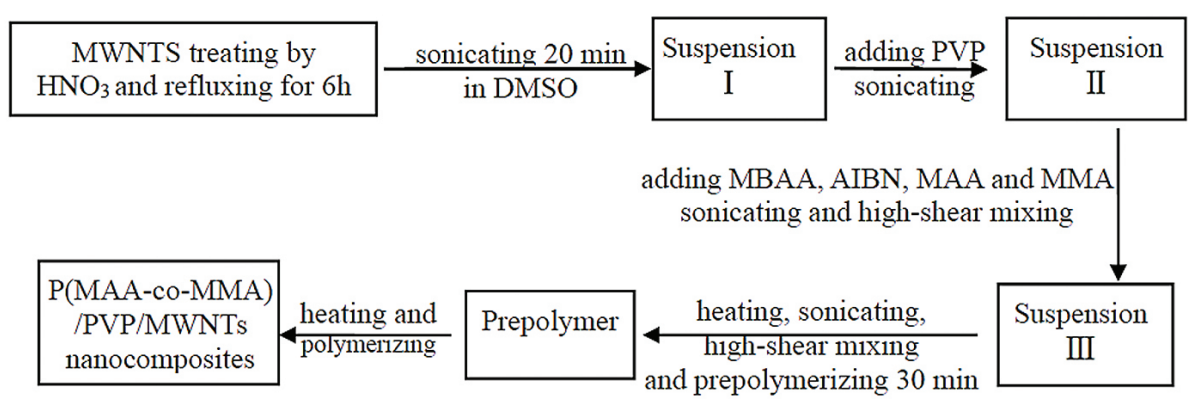

Scheme 1. Synthesis strategy of P(MAA-co-MMA)/PVP/MWNTs nanocomposites. 


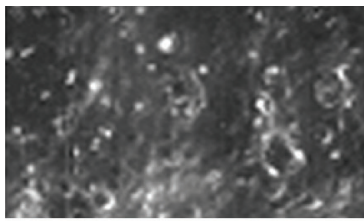

(a)

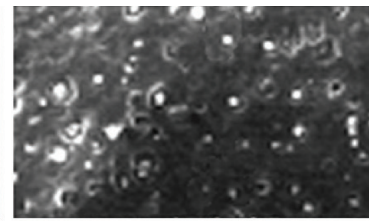

(b)

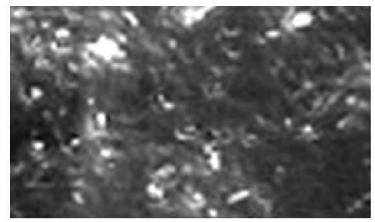

(c)

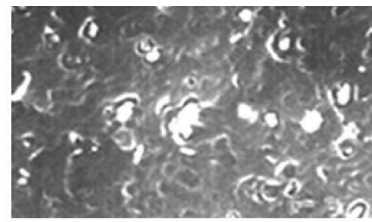

(d)

Figure 2. SEM images of $\mathrm{P}(\mathrm{MAA}-\mathrm{co}-\mathrm{MMA}) / \mathrm{PVP} / \mathrm{MWNTs}$ nanocomposites. a) $\mathrm{P}(\mathrm{MAA}-\mathrm{co}-\mathrm{MMA}) / \mathrm{PVP} / 0.5 \mathrm{wt} \% \mathrm{MWNTs}$, b) P(MAA-co-MMA)/PVP/1wt\% MWNTs, c) P(MAA-co-MMA)/PVP/2wt\% MWNTs, d) P(MAA-co-MMA)/PVP/3.0wt\% MWNTs.

MWNTs is smaller than $100 \mathrm{~nm}$ with average diameters $=68 \mathrm{~nm}$, and about $0.8 \%$ large than $200 \mathrm{~nm}$.

The efficiency of nanofillers in reinforcing the polymer matrix is primarily determined by the degree of its dispersion in the matrix, which influences many properties of polymers/CNTs nanocomposites, including improving the mechanical, electrical, and thermal performances of the polymer matrix. Therefore, morphological characterization is very important for the evaluation of the dispersion state of carbon nanotubes in the polymer matrix. In this study, SEM observations were performed for cryo-fractured surfaces of P(MAAco-MMA)/PVP/MWNTs nanocomposites, as shown in Figure 2a-d. A fibrous fractured surface is observed due to the elongation at break of P(MAA-co-MMA)/PVP/ MWNTs nanocomposites; the random dispersed bright dots because of MWNTs high conductivity are the ends of the broken carbon nanotubes ${ }^{[22]}$. In addition, it is found that some MWNTs are broken apart, and, as a result of poor interfacial adhesion, some MWNTs are pulled out of the matrix before the breakage, forming caves on the fractured surface; moreover, other MWNTs are observed with their one end still strongly embedded in the P(MAAco-MMA)/PVP blends as an inset. Such interesting and typical breakage phenomenon of the MWNTs indicates that a strong interfacial adhesion exists between MWNTs and P(MAA-co-MMA)/PVP blends and that the load transfer takes place efficiently from the matrix to the nanotubes. The strong interfacial adhesion is usually responsible for the significant enhancement of the dynamic mechanical properties ${ }^{[23]}$.

At low concentration of MWNTs, from Figures 2a, b, and c, it can be seen that the bright dots (i.e., MWNTs) embedded in P(MAA-co-MMA)/PVP blends and the caves (i.e., MWNTs) pulled out from P(MAA-co-MMA)/ PVP blends are well dispersed; however, with an increase in MWNTs concentration, from Figure 2d, a nonuniform dispersion of MWNTs is observed in the nanocomposites, and a large aggregate of MWNTs having a diameter of over $500 \mathrm{~nm}$ is presented; while in the case of pristine MWNTs, its diameter is about $70 \mathrm{~nm}$, as shown in Figure 1. Those indicate that MWNTs were dispersed as nanotubes aggregates due to the imperfect dispersion of MWNTs.

When the content of MWNTs is no more than $2.0 \mathrm{wt} \%$, the MWNTs are well dispersed with few aggregations under ultrasonic treatment ${ }^{[24]}$; on the other hand, owing to producing carboxylic or hydroxylic groups on the surface of the MWNTs by HNO3 treatment, which ensures the high dispersion quality of the MWNTs and prevents the severe aggregation of MWNTs ${ }^{[25]}$, reasonably uniform distribution of the MWNTs is observed in Figures 2a, $\mathrm{b}$, and c. Meanwhile, at compositions containing greater amounts of MWNTs, a small amount of aggregates is shown in Figure 2d. These results are in good agreement with the results of $\mathrm{Wu}$ et al. and Bikiaris et al. who reported that increasing the content of $\mathrm{SiO} 2$ leads to larger agglomerate ${ }^{[26,27]}$; this is also the case in P(MAAco-MMA)/PVP/MWNTs nanocomposites.

In fact, there are more or less agglomerates of MWNTs formed in Figure 2d. It is worth noting, due to the strong interaction among the nanoparticles and the higher concentration of MWNTs, the limited shear force provided by the mixing device might be impossible to obtain an efficient nanoscale dispersion of MWNTs.

Even at low volume fractions, the vast interfacial area created by well-dispersed nanoparticles can affect the behaviour of the surrounding polymer matrix, creating a co-continuous network of dramatically altered polymer chains, and fundamentally changing the mechanical and thermal properties of the matrix ${ }^{[28,29]}$. The temperature-dependence plots of the storage modulus (E') of P(MAA-co-MMA)/PVP blends and P(MAAco-MMA)/PVP/MWNTs nanocomposites, as measured from 18 to $142{ }^{\circ} \mathrm{C}$, are shown in Figure 3, where each value is an average of 5 experimental results. As shown in Figure 3, the glassy-state storage modulus E' (at $18{ }^{\circ} \mathrm{C}$ ) of P(MAA-co-MMA)/PVP/MWNTs nanocomposites at $0.5,1,2$, and 3 wt $\%$ MWNTs loading increases by 22 , 41,64 , and $112 \%$ beyond that of P(MAA-co-MMA)/PVP blends, respectively. It is clear that the average glassystate modulus increases with increasing filler weight fraction. The enhanced results for MWNTs are attributed to the superior interfacial bonding and persistently good dispersion: as the number of MWNTs increases, they impact the modulus both by their own inherent stiffness as well as by the enhanced stiffness of the increased "interphase" and P(MAA-co-MMA)/PVP blends molecular movements are restricted by the geometric confinement of $\mathrm{MWNTs}^{[30]}$.

The interaction of MWNTs nanofillers with P(MAAco-MMA)/PVP blends significantly increases the nanocomposites's glass transition temperatures $(\mathrm{Tg})$ (identified by location of the loss tangent (Tan $\delta$ ) peak, as shown in Figure 4 by at most as much as $24{ }^{\circ} \mathrm{C}$. As an increase of $\mathrm{Tg}$ is an indication of good dispersion of the nanoparticles and a correspondingly large amount of interfacial area with altered polymer chain mobility throughout P(MAA-co-MMA)/PVP/MWNTs nanocomposites, these data suggest an good dispersion of the nanofiller component in the polymer matrix. 


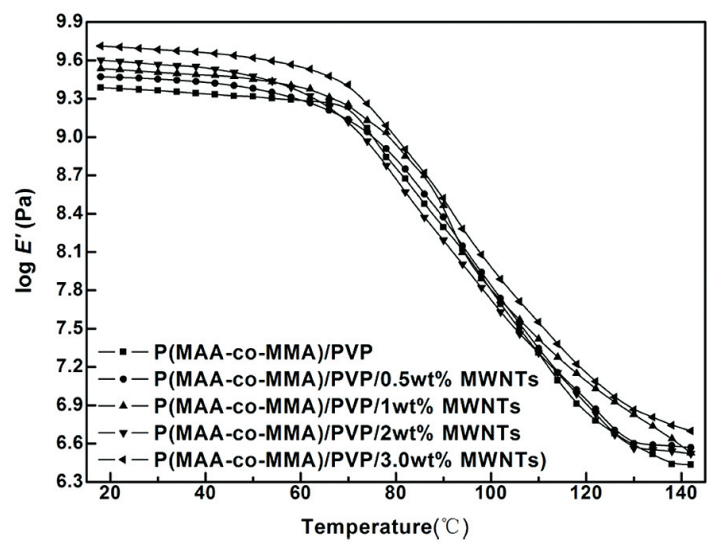

Figure 3. Temperature dependence of tensile storage modulus E' for P(MAA-co-MMA)/PVP and various P(MAA-co-MMA)/ PVP/MWNTs nanocomposites.

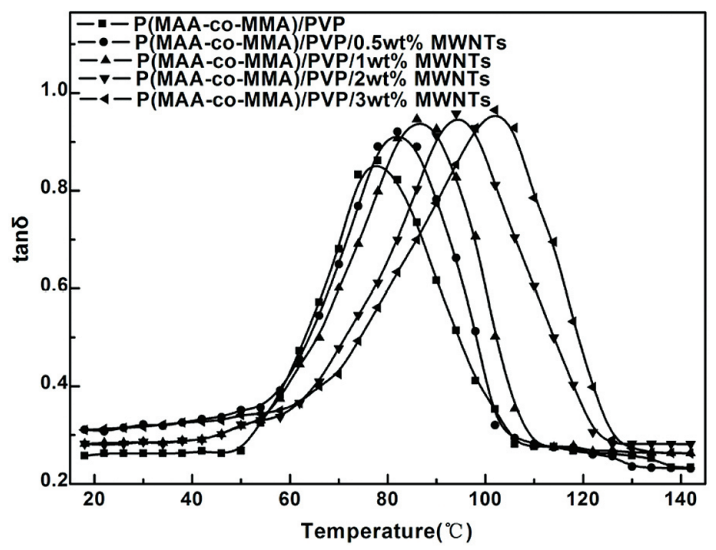

Figure 4. Loss tangent (Tan $\delta)$ as determined by DMA for $\mathrm{P}(\mathrm{MAA}-\mathrm{co}-\mathrm{MMA}) / \mathrm{PVP} / \mathrm{MWNT}$ nanocomposites and P(MAAco-MMA)/PVP blends.

The Tg continuously increases with in creasing filler content. This can be attributed to the smaller particle size, higher surface area, and greater surface roughness of the MWNTs particles that strongly attract the polymer molecules, eliminating the weak interfaces observed in the other systems. This consistent strong interaction between polymer and MWNTs reduces the polymer chain mobility and facilitates good dispersion at all filler loadings. Consequently, the amount of interfacial area between polymer and MWNTs increases with MWNTs content, causing a steady increase in $\mathrm{Tg}$ as well as more modest increases in modulus. On the other hand, the tan of P(MAA-co-MMA)/PVP/MWNTs nanocomposites is improved as compared to $\mathrm{P}(\mathrm{MAA}-\mathrm{co}-\mathrm{MMA}) / \mathrm{PVP}$ blends. Since the tan corresponds to the strain energy dissipated by viscous friction, a large tan implies that the material is more likely to be viscous than elastic. This may be attributed to MWNTs acting as physical crosslinks, which partially restricted molecular movements of polymer and increased the stiffness of P(MAA-coMMA)/PVP/MWNTs nanocomposites.

Figure 5 shows TGA thermograms of $\mathrm{P}(\mathrm{MAA}-\mathrm{co}-$ MMA)/PVP blends, MWNTs and P(MAA-co-MMA)/

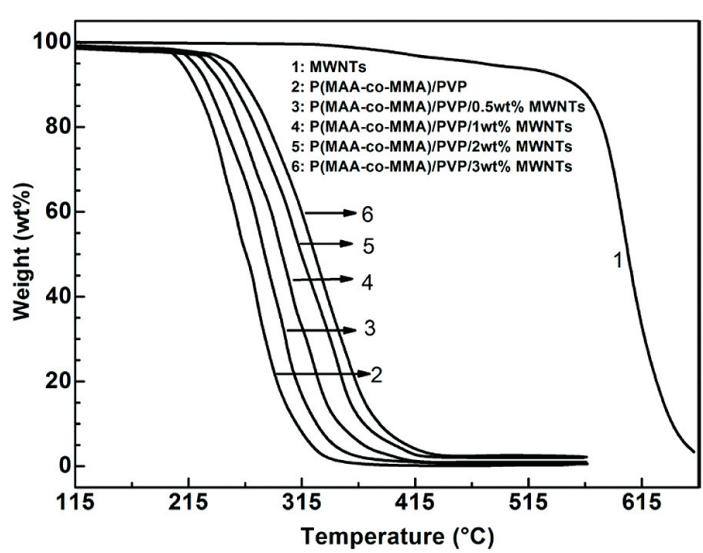

Figure 5. TGA curves of MWNTs, $\mathrm{P}(\mathrm{MAA}-\mathrm{co}-\mathrm{MMA}) / \mathrm{PVP}$ blends and P(MAA-co-MMA)/PVP/MWNTs nanocomposites.

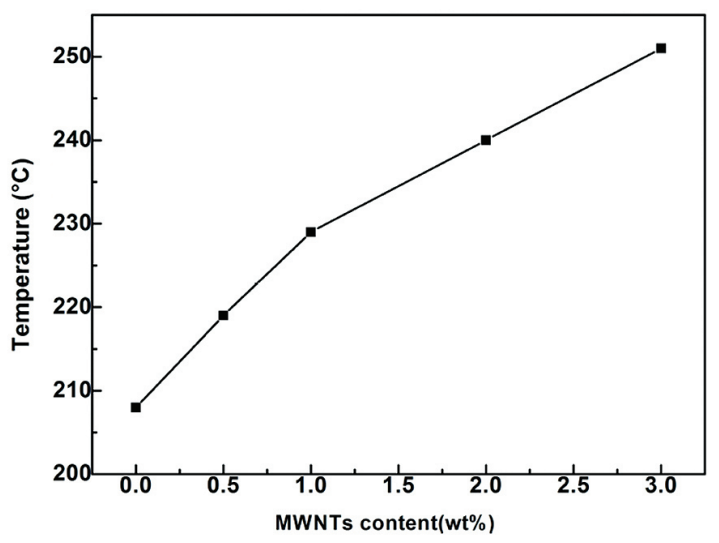

Figure 6. Decomposition temperature (Td, 5\% weight loss temperature) as a function of MWNTs loading.

PVP/MWNTs nanocomposites. The decomposition temperature (onset of inflection) for P(MAA-co-MMA)/ PVP blends is lower than those of its nanocomposites, indicating that the thermal stability of nanocomposites has been improved because of addition of MWNTs. Besides that, the residual weight of $\mathrm{P}(\mathrm{MAA}-\mathrm{co}-\mathrm{MMA}) / \mathrm{PVP} /$ MWNTs nanocomposites left increases steadily with the increase of MWNTs loading. As shown in Figure 5, the weight loss at $300{ }^{\circ} \mathrm{C}$ for P(MAA-co-MMA)/PVP blends is about $85 \%$, whereas $\mathrm{P}(\mathrm{MAA}-\mathrm{co}-\mathrm{MMA}) / \mathrm{PVP} / \mathrm{MWNT}$ nanocomposites are only around $30-70 \%$. This also indicates that the thermal stability of P(MAA-co-MMA)/ PVP blends is significantly improved on incorporation of MWNTs.

Figure 6 shows the dependence of the decomposition temperature (Td, $5 \%$ weight loss temperature) on MWNTs content. P(MAA-co-MMA)/PVP blends and MWNTs start to loss weight at $208{ }^{\circ} \mathrm{C}$ and $467{ }^{\circ} \mathrm{C}$, respectively. It can be seen that the overall thermal stability of P(MAAco-MMA)/PVP/MWNTs nanocomposites, compared with $\mathrm{P}(\mathrm{MAA}-\mathrm{co}-\mathrm{MMA}) / \mathrm{PVP}$ blends, is clearly improved; in Figure 6, the addition of $0.5 \mathrm{wt} \%$ MWNTs causes the decomposition temperature of P(MAA-co-MMA)/PVP/ 


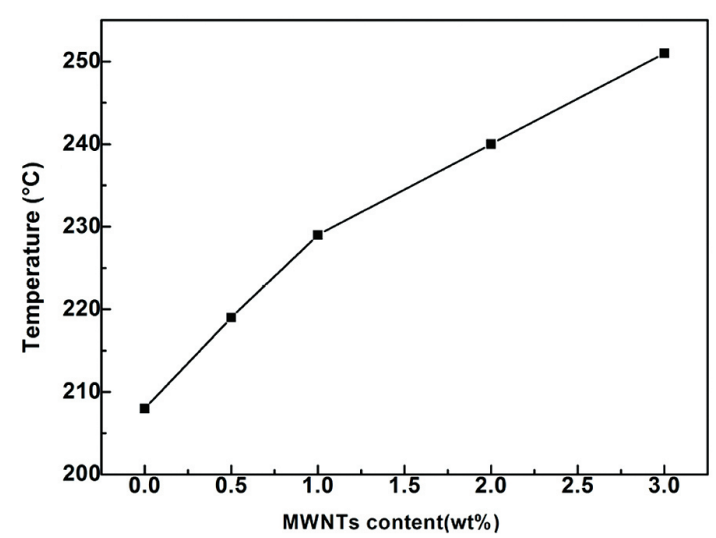

Figure 7. Equilibrium degree of swelling of P(MAA-co-MMA)/ PVP/MWNTs nanocomposite gels.

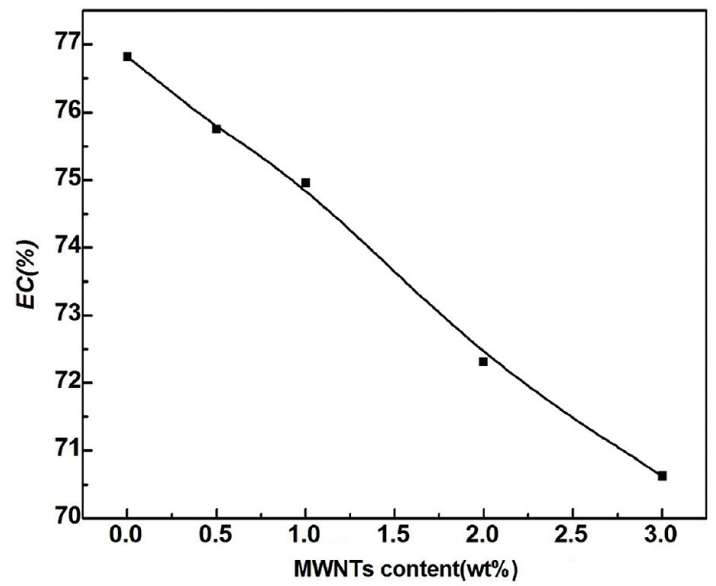

Figure 8. Equilibrium water content of $\mathrm{P}(\mathrm{MAA}-\mathrm{co}-\mathrm{MMA}) / \mathrm{PVP} /$ MWNTs nanocomposite gels.

MWNTs nanocomposites increase more than $10{ }^{\circ} \mathrm{C}$. The thermal stability of P(MAA-co-MMA)/PVP/MWNTs nanocomposites may be closely related to following factors: the dispersion state and the loading content of MWNTs. The decomposition temperature of P(MAA-coMMA)/PVP/MWNTs nanocomposites increases slightly with increasing MWNTs loading content, probably due to the ease of compact char formation for the nanocomposites during the thermal degradation. On the other hand, high concentration MWNTs would definitely prevent its fine dispersion, and more aggregation or bundles could often be formed because of van der Waals force among the MWNTs, thus deteriorating the thermal stability of the nanocomposites. It is necessary to research the competing effect between the dispersion state and the loading content of MWNTs in depth.

P(MAA-co-MMA)/PVP/MWNTs nanocomposites have three-dimensional polymer networks, i.e., crosslinked P(MAA-co-MMA) gels, which may be used for potential biomaterials, such as wound dressing. In this work, the equilibrium degree of swelling $(E S)$ and equilibrium water content $(E C)$, as important swelling characteristics of $\mathrm{P}(\mathrm{MAA}-\mathrm{co}-\mathrm{MMA}) / \mathrm{PVP} / \mathrm{MWNTs}$ nanocomposite gels, were measured. These characteristics indicated the ability of P(MAA-co-MMA)/PVP/MWNTs nanocomposite gels in absorption of fluids. Figure 7 and Figure 8 demonstrate $E S$ and $E C$ of P(MAA-co-MMA)/ PVP/MWNTs nanocomposite gels as a function of the amount of MWNTs. Both parameters show nearly similar decreasing trends by increasing the quantity of MWNTs. Although the swelling characteristics of P(MAA-coMMA)/PVP/MWNTs nanocomposite gels decrease due to presence of MWNTs in comparison with $\mathrm{P}(\mathrm{MAA}-\mathrm{co}-$ MMA)/PVP hydrogel, but it seems that they have high enough swelling capacity. This effect may be caused due to incorporation MWNTs into P(MAA-co-MMA)/ PVP hydrogel, dispersing in hydrogel and decreasing the polymer free volume, thus reducing the swelling of P(MAA-co-MMA)/PVP/MWNTs nanocomposite gels.

\section{Conclusion}

P(MAA-co-MMA)/PVP/MWNTs nanocomposites with various MWNTs contents were prepared by ultrasonic assisted solution free radical polymerization. SEM, DMA, TGA, and swelling tests were used to investigate the morphology and the properties of P(MAA-co-MMA)/PVP/MWNTs nanocomposites. SEM analysis shows that, at low concentration of MWNTs, it is well dispersed; however, with an increase in MWNTs concentration, it is a nonuniform dispersion, and a large aggregate of MWNTs having a diameter of over $500 \mathrm{~nm}$ is formed. DMA tests showed that the E' and Tg of P(MAAco-MMA)/PVP/MWNTs nanocomposites increased with the increasing MWNTs content. The analysis of thermal degradation in airflow showed a clear improvement of thermal stability for P(MAA-co-MMA)/PVP/MWNTs nanocomposites, proportionally to MWNTs content. Although the swelling characteristics of P(MAA-coMMA)/PVP/MWNTs nanocomposite gels decrease, it may be used for potential wound dressing.

\section{References}

1. Han, W. \& Lin, Z. W. - Angew. Chem. Int. Ed., 51, p.1534 (2012). PMid:22311809. http://dx.doi.org/10.1002/ anie. 201104454

2. Mao, L.; Zhang K. \& Chan, H. S. O. - J. Mater. Chem., 22, p.80 (2012). http://dx.doi.org/10.1039/c1jm12869h

3. Alig, I.; Poetschke, P. \& Lellinger, D. - Polymer, 53, p.4 (2012). http://dx.doi.org/10.1016/j.polymer.2011.10.063

4. Juan-Alcaniz, J.; Gascon, J. \& Kapteijn, F. - J. Mater. Chem., 22, p.10102 (2012). http://dx.doi.org/10.1039/ c2jm15563j

5. Zou, Y. B.; Feng, Y. C.; Wang, L. \& Liu, X. B. - Carbon, 42, p.271 (2004). http://dx.doi.org/10.1016/j. carbon.2003.10.028

6. Yeh, M. K.; Tai, N. H. \& Liu, J. H. - Carbon, 44, p.1 (2006). http://dx.doi.org/10.1016/j.carbon.2005.07.005

7. Grossiord, N.; Loos, J.; Regev, O. \& Koning, C. E. - Chem. Mater., 18, p.1089 (2006). http://dx.doi.org/10.1021/ $\mathrm{cm} 051881 \mathrm{~h}$

8. Kim, S. T.; Lim, J. Y.; Park, B. J. \& Choi, H. J. - Macromol. Chem. Phys., 208, p.514 (2007). http://dx.doi.org/10.1002/ macp. 200600543 
9. Zhang, F. H.; Wang, R. G.; He, X. D.; Wang, C. \& Ren, L. N. - J. Mater. Sci., 44, p.3574 (2009). http://dx.doi. org/10.1007/s10853-009-3484-x

10. Gojny, F. H.; Wichmann, M. H. G.; Fiedler, B.; Bauhofer, W. \& Schulte, K. - Compos. Part A, Appl. Sci. Manuf., 36, p.1525 (2005). http://dx.doi.org/10.1016/j. compositesa.2005.02.007

11. Bonnet, P.; Sireude, D.; Garnier, B. \& Chauvet, O. - Appl. Phys. Lett., 91, p.201910 (2007). http://dx.doi. org/10.1063/1.2813625

12. Chang, C. M. \& Liu, Y. L. - ACS Appl. Mater. Interfaces, 3, p.2204 (2011). PMid:21644521. http://dx.doi.org/10.1021/ am200558f

13. He, X. Q.; Kitipornchai, S.; Wang, C. M. \& Leiw, K. M. - Int. J. Solids Struct., 42, p.6032 (2005). http://dx.doi. org/10.1016/j.ijsolstr.2005.03.045

14. Wepasnick, K. A.; Smith, B. A.; Bitter, J. L. \& Fairbrother, D. H. - Anal. Bioanal. Chem., 396, p.1003 (2010). PMid:20052581. http://dx.doi.org/10.1007/s00216-009$3332-5$

15. Coleman, J. N.; Khan, U.; Blau, J. \& Gun'ko, Y. - Carbon, 44, p.1624 (2006). http://dx.doi.org/10.1016/j. carbon.2006.02.038

16. Jeon, J. H.; Lim, J. H. \& Kim, K. M. - Polymer, 50, p.4488 (2009). http://dx.doi.org/10.1016/j.polymer.2009.07.033

17. Lee, W. I.; Kim, S. H. \& Park, J. M. - Carbon, 47, p.2699 (2009).

18. Inal, M. \& Yigitoglu, M. - Appl. Biochem. Biotechnol., 168, p.266 (2012). PMid:22717770. http://dx.doi.org/10.1007/ s12010-012-9770-0

19. Aldana, A. A.; Gonzalez, A.; Strumia, M. C. \& Martinelli, M. - Mater. Chem. Phys., 134, p.317 (2012). http://dx.doi. org/10.1016/j.matchemphys.2012.02.071
20. Lowman, A. M. \& Peppas, N. A. - Polymer, 41, p.73 (2000). http://dx.doi.org/10.1016/S0032-3861(99)00159-7

21. Liu, S. X.; Fang, Y.; Hu, D. \& Gao, G. - J. Appl. Polym. Sci., 82, p.620 (2001). http://dx.doi.org/10.1002/app.1890

22. Chen, D.; Wang, M.; Zhang, W. D. \& Liu, T. - J. Appl. Polym. Sci, 113, p.644 (2009).

23. Chen, G. X.; Kim, H. S.; Park, B. H. \& Yoon, J. S. - Polymer, 47, p.4760 (2006). http://dx.doi.org/10.1016/j. polymer.2006.04.020

24. Kim, S. T.; Choi, H. J. \& Hong, S. M. - Colloid Polym. Sci., 285, p.593 (2007). http://dx.doi.org/10.1007/s00396006-1599-Z

25. Zhao, Y.; Qiu Z. \& Yang, W. - J. Phys. Chem. B, 112, p.16461 (2008). PMid:19055414. http://dx.doi. org/10.1021/jp805230e

26. Wu, C. L.; Zhang, M. Q.; Rong, M. Z. \& Friedrich, K. - Compos. Sci. Technol., 62, p.1327 (2002). http:// dx.doi.org/10.1016/S0266-3538(02)00079-9

27. Bikiaris, D. N.; Vassiliou, A.; Pavlidou, E. \& Karayannidis, P. - Eur. Polym. J., 41, p.1965 (2005). http://dx.doi. org/10.1016/j.eurpolymj.2005.03.008

28. Ramanathan, T.; Liu, H. \& Brinson, L. C. - J. Polym. Sci. Part B, Polym. Phys., 43, p.2269 (2005). http://dx.doi. org/10.1002/polb.20510

29. Bansal, A.; Yang, H.; Li, C.; Cho, K.; Benicewicz, B. C.; Kuma. S. K. \& Schadler, L. S. - Nature Mater., 4, p.693 (2005). PMid:16086021. http://dx.doi.org/10.1038/ nmat 1447

30. Yang, J.; Wang, C.; Wang, K.; Zhang, Q.; Chen, F. \& Du, Q. - Macromolecules, 42, p.7016 (2009).

Received: 03/24/13

Revised: $11 / 27 / 13$

Accepted: 12/02/13 